\title{
Alkyl Sulfates as Precursors of Ascidian Flavor in Halocynthia roretzi
}

\author{
Kenshiro Fujmoto*, Hideo Ohromo*, Ayako KanaZAWA*, \\ Yumiko KIKUCH *, and Takashi KANEDA* \\ (Received February 5, 1982)
}

\begin{abstract}
In the preceding paper, the enzymatic formation of the ascidian flavor derived from $n$-alcohols in viscera of Halocynthia roretzi was demonstrated. This paper deals with the isolation and identification of the precursors responsible for the flavor formation. The precursors have been isolated from the ethanol extracts of viscera by using solvent fractionation and chromatographic techniques. Each fraction was assayed for the activity of octanol generation in reaction with crude enzyme.

The precursors have been identified as salts of alkyl sulfates with carbon atoms 8 to 10 . The structures were confirmed by elementary analyses, composition of hydrolysis products, and direct comparison of IR spectra and Rf values on TLC with those of an authentic sample. The role of alkyl sulfates in the ascidian is also discussed.
\end{abstract}

The ascidian Halocynthia roretzi is well known for the peculiar "ascidian" flavor derived from $n$-alcohols. ${ }^{1,2}$ In a previous paper, ${ }^{3)}$ the enzymatic formation of the ascidian flavor from some types fo precursors contained in the ascidian viscera was reported. The present investigation deals with identifying the precursors and solving the mechanism for the flavor formation in the ascidian. Various fractions prepared from viscera were reacted with an enzyme preparation, and the fraction which generated octanol, one of the major alcohol responsible for the ascidian flavor, was purified by various chromatographic techniques. The purified precursors and their decomposition products were submitted to several types of instrumental analyses and their presumed structures were confirmed by comparison with the authentic specimen.

\section{Materials and Methods}

\section{Materials}

Halocynthia roretzi were obtained from Okatsu, Miyagi-Prefecture in June. While still alive the ascidian were removed from the tunics and anatomized to acquire the viscera. After removing the gut contents with sea water, the viscera was utilized for preparation of both the substrate and crude enzyme.

\section{Preparation of Enzyme and Conditions for En-} zymatic Reaction

The enzyme for the flavor formation was prepared as an acetone powder described in the preceding paper. ${ }^{3)}$ Various substrates were reacted with the enzyme according to the method originally employed for the assay of esterase activity by FIORE and NORD ${ }^{4)}$ with some modifications. $^{3\rangle}$ The intensity of the ascidian flavor was expressed as the concentrations of octanol determined by the steam distillation-GLC method as described previously. ${ }^{3)}$ In the standard reaction system, $20 \mathrm{mg}$ of each substrate was reacted with $200 \mathrm{mg}$ of the enzyme. As the substrates differed among each other in the levels of original free octanol, the enzymatic-formed octanol was calculated by deducting the amount of octanol before the reaction from the amount of octanol after it.

\section{Isolation of Precursors}

The precursors of the ascidian flavor were first extracted with ethanol from viscera $(13.8 \mathrm{~kg})$. The ethanol extracts were fractionated as schematically outlined in Fig. 1. Being labile by heating in an acidic solution, the solutions of precursors were concentrated at temperature below $40^{\circ} \mathrm{C}$ and neutralized with diluted $\mathrm{NH}_{4} \mathrm{OH}$ if the extracts turned out to be acidic. Each fraction was

* Department of Food Chemistry, Faculty of Agriculture, Tohoku University, Tsutsumidori-Amamiya-

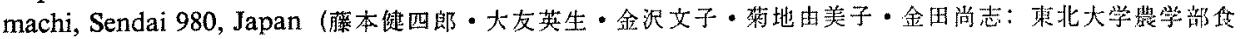
糧化学科). 


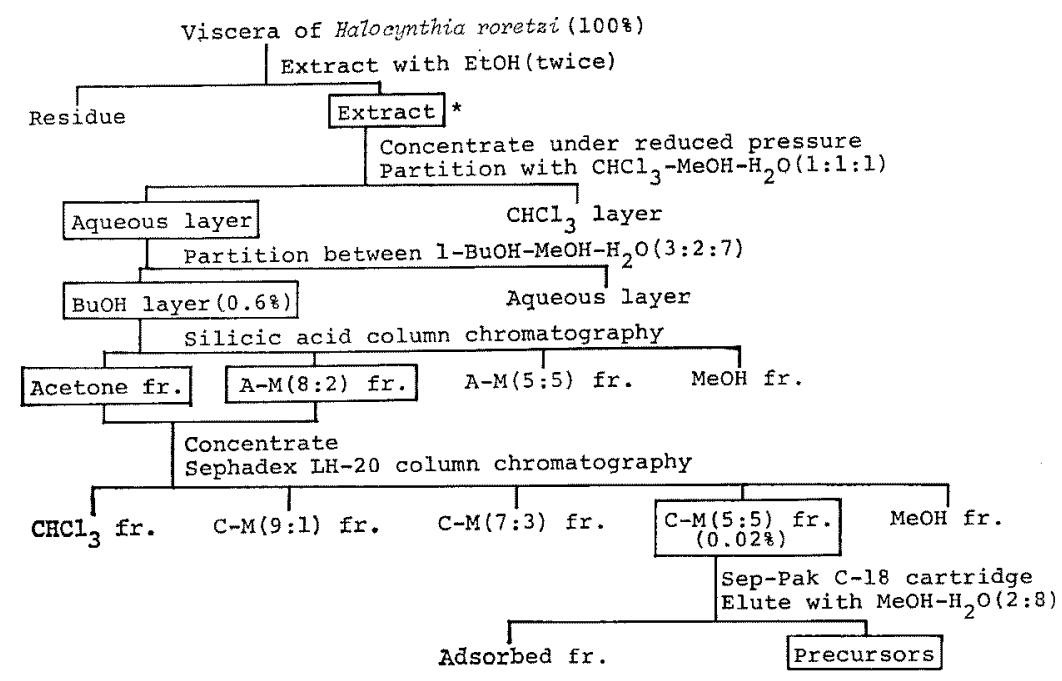

Fig. 1. Purification procedure for the precursors of the peculiar ascidian flavor in Halocynthia roretzi.

—* Fractions generated octanol by the reaction with crude enzyme.

developed on TLC and assayed for the activity of octanol generation by the enzymatic reaction. For silicic acid column chromatography, a column of Wakogel C-100 (Wako Pure Chem., $2.5 \mathrm{~kg}$ ) was utilized. The column loaded with the sample $(35 \mathrm{~g})$ was first washed with acetone $(9 l)$, and successively eluted with acetone-methanol $(4: 1,10 l)$, acetone-methanol $(1: 1,4 l)$ and finally with methanol $(6 l)$. The active fractions were combined, evaporated and then applied on a Sephadex LH-20 (Pharmacia Fine Chem.) column $(50 \mathrm{~g})$. The following solvents composed of chloroform (C) and methanol (M) were used for elution: 1) C $500 \mathrm{ml}$, 2) C-M(9:1) $1000 \mathrm{ml}$, 3) $\mathrm{C}-\mathrm{M}(7: 3) 1000 \mathrm{ml}$, 4) C-M(5:5) $1000 \mathrm{ml}$, 5) $\mathrm{M} 1000 \mathrm{~m} /$. The active fraction produced by the Sephadex column was successively applied to a Sep-Pak Cartridge C-18 (Waters Assoc. Inc.) to eliminate the contaminated colored substances.

\section{Thin Layer Chromatography}

The purified precursors, their degradative products, and authentic specimens of octanol and sodium octyl sulfate were developed on plates of Wakogel B-5 (Wako Pure Chem., $0.25 \mathrm{~mm}$ ) with the solvent systems listed below: (a) chloroformmethanol-water $(65: 25: 4)$, (b) 1-butanol-acetic acid-water $(3: 1: 1)$, (c) chloroform-methanol$28 \% \quad \mathrm{NH}_{4} \mathrm{OH} \quad(65: 35: 5)$, (d) $n$-hexane-diethyl ether $(7: 2)$. Developed plates were visualized with $50 \%$ sulfuric acid or anthrone reagent.

Determination of Mean Molecular Weight (MMW) of Precursors

MMW of the precursors was determined by the vapor pressure equilibrium method using methanol on a Hitachi Perkin-Elmer model 115 apparatus.

\section{Decomposition of Precursors}

Precursors were hydrolyzed or reductively decomposed with several method as listed below: (a) $0.01 \mathrm{~N} \mathrm{HCl}$ in methanol-water $(1: 1)$ at $60^{\circ} \mathrm{C}$ for $14 \mathrm{~h},{ }^{5)}$ (b) acetone-water $(4: 1)$ at $60^{\circ} \mathrm{C}$ for $3 \mathrm{~h},{ }^{8)}$ (c) reduction with $\mathrm{LiAlH}_{4}{ }^{7}$ ) After these reactions. the diethyl ether-soluble fractions were submitted to TLC analysis to identify the degraded products. The amount of sulfate liberated with acid hydrolysis was determined according to the method described by MAYER et al. ${ }^{83}$

\section{Preparation of Sodium Salts of Hydrogenated Precursors}

The precursors dissolved in methanol were hydrogenated in an atmosphere of hydrogen in the presence of paradium black catalyst at room temperature for $24 \mathrm{~h}$. Hydrogenated precursors were successively transformed to sodium salts by passage through a column of Dowex $50 \times 4\left(\mathrm{H}^{+}\right.$type) and successive neutralization with $0.1 \mathrm{~N} \mathrm{Na}_{2} \mathrm{CO}_{3}$ 
Table 1. Mean molecular weight and elementary analysis of the precursors

\begin{tabular}{ccc}
\hline Mean molecular weight & 256 & \\
\hline $\begin{array}{c}\text { Elementary } \\
\text { analysis }\end{array}$ & $\%$ & $\begin{array}{c}\text { Number of } \\
\text { atoms/molecule }\end{array}$ \\
\hline $\mathrm{C}$ & 42.57 & 9.1 \\
$\mathrm{H}$ & 8.01 & 20.5 \\
$\mathrm{~N}$ & 0.89 & 0.16 \\
$\mathrm{~S}$ & 12.01 & 0.96 \\
$\mathrm{P}$ & 0 & 0 \\
Ash & 11.52 & \\
Sulfate-S & 12.5 & 1.00 \\
\hline
\end{tabular}

solution.

\section{Synthesis of Sodium Octyl Sulfate}

Monooctyl sulfate prepared from 1-octanol and fuming sulfric acid was neutralized with $\mathrm{NaHCO}_{3}$, and purified by chromatography on a Sephadex LH-20 column.

Gas Chromatography-Mass Spectrometry (GC-MS) of Alcohols Liberated from Precursors

Alcohols provided by acid hydrolysis of the precursors and their hydrogenated derivatives were submitted to GC-MS (Shimadzu LKB-9000: $4 \mathrm{~mm} \times 100 \mathrm{~cm}$, Chromosorb W coated with $20 \%$ $\mathrm{PEG}$; temp., $150^{\circ} \mathrm{C}$; carrier gas, helium; ionization $25 \mathrm{eV}$ ).

\section{Results and Discussion}

\section{Isolation of Precursors}

The purification procedure of the precursors of the ascidian flavor is schematically shown in Fig. 1. By extraction with the mixture of chlorofrommethanol-water (1:1:1), being principally distributed in the aqueous methanol layer, it was possible to separate the precursors from most of the lipids. Therefore, they were found to be very polar and different from common lipids including waxes. Also they were isolated from aqueous compounds by 1-butanol extraction. After successive column chromatography, the active fraction gave a single spot on TLC by sulfuric acid as shown in Fig. 2, The yield of this fraction in ethanol extracts was $0.13 \%$.

\section{Properties and Identification of Precursors}

The purified precursors were obtained as a colorless powder without any peculiar odor. They were almost negative with the coloring

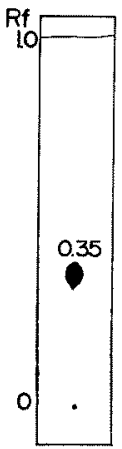

(a)

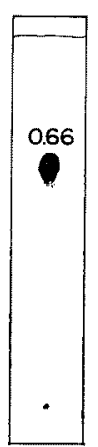

(b)

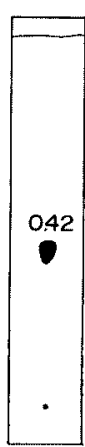

(c)
Fig. 2. Thin layer chromatography of the precursors. See text for the compositions of solvents.

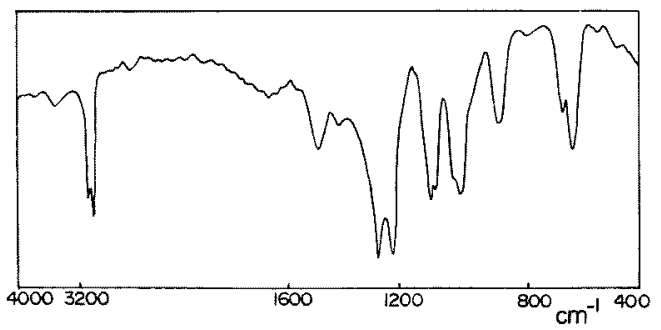

Fig. 3. IR spectrum of the precursors.

tests $^{(3)}$ commonly used for various lipids. However, with anthrone reagent alone, they gave a characteristic pale brown color which was different from the typical color (purple) developed with glycolipids. They also colorated in faint yellow with 2,4-dinitrophenylhydrazine (DNPH) after several minutes. Infrared spectrum indicated the absence of the absorptions in the ester carbonyl and amide regions, suggesting the alcohols were not generated by the hydrolysis of these linkages (Fig. 3). Hydroxy groups were not recognized either. The absorptions at 1250, 1210, 1070, 980 and $830 \mathrm{~cm}^{-1}$ strongly suggested the occurrence of a sulfate group. ${ }^{10}$ However, the possibility of the presence of a vinyl ether moiety could not be discarded because of the absorption at 1250 $\mathrm{cm}^{-1}$ and the coloring with 2,4-DNPH.

Elementary analysis showed the presence of sulfur whose amount corresponded to one atom per one molecule calculated from the mean molecular weight (MMW) (256). Because the value of sulfate-S was in fair agreement with that of the total-S $(12.0 \%)$, sulfur was found to exist as a sulfate ester. A high content of ash indicated 
Table 2. Alcohol composition of the precursors determined by GC-MS

\begin{tabular}{rccll}
\hline $\begin{array}{c}\text { Peak } \\
\text { No. }\end{array}$ & $\begin{array}{c}\text { Relative } \\
\text { retention } \\
\text { time }\end{array}$ & $\begin{array}{c}\text { Ratio } \\
(\%)\end{array}$ & Assignnent & Major fragment ions \\
\hline 1 & 1 & 22 & 1 -octanol & $130,112,68,56,55,43,41$ \\
2 & 1.35 & 6 & 1 -octenol & $128,116,82,67,56,55,43$ \\
3 & 1.63 & 2 & 1-nonanol & $126,98,83,56,55,43,41$ \\
4 & 2.09 & 3 & 1-nonenol(?) & \\
5 & 2.56 & 13 & unknown & $114,98,85,56$ \\
6 & 2.91 & 12 & 1 -decanol & $140,83,69,43,41$ \\
7 & 3.26 & 37 & 1-decenol & $138,95,82,67,55$ \\
8 & 3.95 & 5 & 1-decadienol & $136,108,94,78,67,55,41$ \\
9 & 4.79 & tr & unknown & $120,94,79,67$ \\
10 & 6.28 & unknown & \\
11 & 8.60 & & unknown & \\
\hline
\end{tabular}

that the precursors were salts of acidic sulfate esters. Carbon numbers calculated from the values of elementary anlysis and MMW suggested that the precursors did not contain any other
Solvents (d)

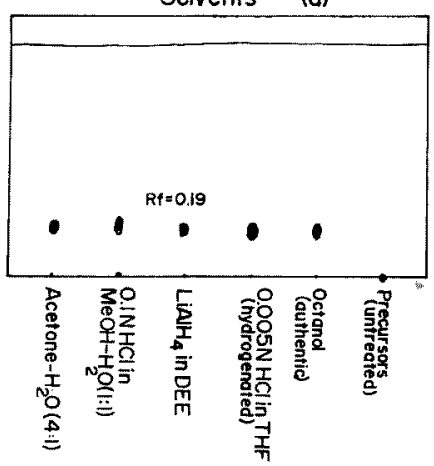

(a)

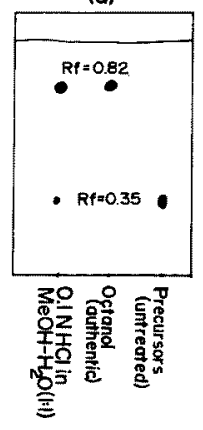

Fig. 4. Thin layer chromatography of the decomposition products obtained by various methods. See text for the composition of solvents. moiety with carbon chains other than an alcohol. This was confirmed by the TLC analysis of the hydrolyzate (Fig. 4).

From the results described above, the precursors were considered to be salts of acidic alkyl sulfates. Therefore, sodium octyl sulfate was synthesized and compared with the precursors in thin layer chromatogram and IR spectrum. The IR spectrum of the precursor was measured after hyrogenation and successive conversion to sodium salts (Fig. 5). The resulting IR spectra and $\mathrm{Rf}$ values on TLC were found to be identical between the two. Therefore, the precursors were definitely identified as alkyl sulfates. The alcohol liberation from synthetic sodium octyl sulfate by the reaction with crude enzyme prepared from the ascidian viscera was also confirmed.

\section{Alcohol Composition of Precursors}

Alcohols generated from the precursors by acid hydrolysis (method; a) were identified by GC-MS (Table 2). The major components were deca-

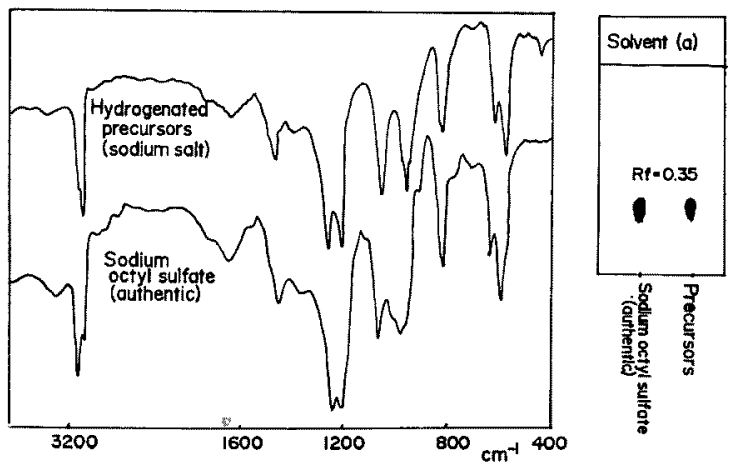

Fig. 5. Comparison of the precursors with synthetic sodium octyl sulfate on thin layer chromatogram and by IR spectra. 
dienol and octanol, which occupied approximately $60 \%$ of the total alcohols, followed by decanol, decenol, and octenol in that order. This alcoholic pattern corresponded well with the data for the alcoholic composition of the ascidian flavor reported by KUSAKA et al., ${ }^{* 1}$ suggesting that the ascidian flavor was exclusively derived from the hydrolysis of these alkyl sulfates.

\section{Role of Alkyl Sulfates in Ascidian}

Alkyl sulfates, being used extensively as synthetic alcoholic-type detergents, were first reported in phytoflagellates by HAINES and co-workers. ${ }^{10)}$ Sulfatides in these series were found to be diols, with 1,14-docosadiol as the main component. Collatz et al. ${ }^{11)}$ reported that in a type of snail, Helix pomatia, alkyl sulfuric esters with carbon numbers 11 to 16 (the main alcohol: $C_{18}, 83 \%$ ) occurred along with partial glycerides in the digestive juice as emulsifiers. Though lithocholic acid was found in scallop, ${ }^{* 2}$ most invertebrates are known to lack bile acids in their digestive juices. ${ }^{123}$ Arthropoda such as lobster, ${ }^{12)}$ cricket and spiders $^{13)}$ contained, instead, fatty acyl-amino acids and/or dipeptides. The detailed distribution and biological function of alkyl sulfates in the ascidian is still unkown and further investigation is necessary. However, a large amount of free alcohols were found in gut contents. Therefore, alkyl sulfates might be secreted in the digestive juice.

The enzyme responsible for the alcohols' liberation in the ascidian is alkyl sulfohydrolase. This enzyme has been exclusively reported in bacteria genus Pseudomonas in connection with biological decomposition of synthetic emulsifiers. ${ }^{14)}$ To date no paper on alkyl sulfohydrolase has been available in the marine invertebrates including the ascidian, whereas several other sulfatase were reported from various gastropod.

\section{Acknowledgements}

The authors wish to express their sincere gratitude to Associate Professor K. Sekino, Facultly of Agriculture, Tohoku Univ., and Mr. K. OKazakI, Fisheries Res. Lab. of Miyagi Prefecture, for the collection of the ascidian. Also they would like to thank Dr. T. Koyama, Chem. Res. of Nonaqueous Solution, Tohoku Univ., for measurements of GC-MS and Associate Professor Y. Sugawara, Faculty of Agriculture, Tohoku Univ., for valuable suggestions.

\section{References}

1) Y. Suzukı: Tohoku J. Agric. Res., 10, 65-69 (1959).

2) Y. Suzuki: Tohoku J. Agric. Res., 10, 391-395 (1960).

3) K. Fujrmoto, Y. Miyayama, and T. Kaneda: Bull. Japan. Soc. Sci. Fish., 48, 1323-1326 (1982).

4) J. V. FIORE and F. F. NORD: Arch. Biochem., 23, 473-479 (1949).

5) K. A. Karlsson, B. E. Samuelsson, and G. O. SteEn: Eur. J. Biochem., 46, 243-258 (1974).

6) J. MCKenna and J. K. Norymberski: J. Chem. Soc., 1957, 3889-3893.

7) R. Wood and F. SNYder: Lipids, 3, 129-135 (1968).

8) G. M. Mayers, M. Pousada, and T. H. Haines: Biochem., 8, 2981-2986.

9) M. KaTES: Techniques of Lipidology (Japanese ed., translated by T. Yamakawa, K. Saito and A. HAYASHi), Tokyo Kagakudojin, Tokyo, 1975, pp. 138-143.

10) T. H. Halnes: Prog. Chem. Fats Other Lipids, 11, 299-345 (1972).

11) K. G. Collata, G. Mommsen, and T. Mommsen: J. comp. Physiol., 96, 123-129 (1976).

12) D. A. Holwerdia and H. J. Vonk: Comp. Biochem. Physiol, 45B, 51-58 (1973).

13) K. G. Collata and T. Mommsen: J. comp. Physiol., 94, 339-352 (1974).

14) D. J. Shaw, K. S. Dodgson, and G. F. White: Biochem. J., 187, 181-190 (1980).

*1 H. Kusaka, H. Narita, K. Iwata, and S. Ohta: Presented at the Annual Meeting of the Japanese Society of Scientific Fisheries on April, 1980, Tokyo.

*2 A. Idda, K. Oishi, and M. TAKagi: Presented at the Annual Meeting of the Japanese Society of Scientific Fisheries on October, 1981, Tsu, Mie-Prefecture. 